\title{
Documento
}

\section{Constituição brasileira, direitos humanos e educação*}

\author{
Roseli Fischmann \\ Universidade de São Paulo, Faculdade de Educação
}

\section{Apresentação}

Preliminarmente, gostaria de agradecer à ANPEd e à sua Diretoria, na pessoa de sua presidente, a professora Márcia Ângela Aguiar, pelo convite para proferir esta conferência em momento tão honroso, seja pelo significado das reuniões anuais da ANPEd, seja pelo tema específico deste ano e seu significado para mim. Mas, como bem afirmado pela Diretoria da ANPEd, na apresentação desta reunião anual: "Nesse espaço da $31^{\text {a }}$ Reunião Anual, serão celebrados os Direitos Humanos e a Constituição Brasileira, cujos parâmetros podem ser apreendidos no conjunto da produção científica da área, e, cada vez mais, afirmados e defendidos nas manifestações político-acadêmicas dos grupos que constituem a ANPEd".

Ora (fiquei pensando, ao receber o convite), se o tema é de todas as áreas da ANPEd - e o é, e isso historicamente -, o que se poderia dizer nesta abertura

${ }^{*}$ Conferência de abertura na 31 ${ }^{\text {a }}$ Reunião Anual da ANPEd, realizada de 16 a 20 de outubro de 2008, em Caxambu (MG). Foi mantido o tom oral da conferência. que pudesse ser uma contribuição? Lembrei-me então de um texto de Hannah Arendt (1987), essa filósofa que tanto tenho estudado, a cada vez me revelando algo novo. É sobre a amizade. Está no livro Homens em tempos sombrios; é o texto dedicado a Gotthold Ephraim Lessing, dramaturgo, filósofo dedicado à estética e crítico de arte, que viveu na Alemanha no século 18.

Lessing afirmava que o lugar da verdade era onde as pessoas podem, cada qual, dizer às demais o que "acha que é verdade", frase que, lembra Arendt (1987, p. 36), “é praticamente impossível na solidão”; poder efetivamente cada um dizer o que "acha que é verdade”, para autora, tanto une como separa os seres humanos, estabelecendo aquelas distâncias (entre as pessoas) que, juntas, compreendem o mundo. Nesse espaço intermediário, no qual cada pessoa se sente livre e confortável para poder dizer em confiança ao amigo “o que acha que é verdade”, é que se constitui verdadeiramente a amizade, constituindo o mundo em sua humanidade e propiciando a busca conjunta da verdade. Por isso, qualquer doutrina ou princípio que tentasse barrar a possibilidade de amizade entre dois 
seres humanos corresponderia a eliminar as possibilidades da pluralidade e, assim, a eliminar o mundo.

Ao lembrar que Lessing permitiu entender "a relevância política da amizade" (Arendt, 1987, p. 31), Arendt afirma que "a humanidade se exemplifica não na fraternidade, mas na amizade; que a amizade não é intimamente pessoal, mas faz exigências políticas e preserva a referência ao mundo [...]”. A ênfase na fraternidade seria ênfase no mesmo, no homogêneo, reduzindo a pluralidade à singularidade. Porque não busca a identificação de um com o outro, que só interessa à esfera privada, da amizade tomada em sentido mais íntimo e afetivo, a amizade, nesse sentido político, permite a manutenção da diferença e da diversidade, fomentando o diálogo e o debate em campo público. Por isso, a amizade, nesse sentido político, pode ser considerada a base da humanização do mundo e da democracia, não exigindo concordância e homogeneidade, mas, ao contrário, possibilitando abertura para a pluralidade, que se manifesta no diálogo em confiança e na busca da verdade pelo debate.

Assim entendo este espaço e passo a expor "o que acho que é verdade” quanto ao tema desta conferência, como minha contribuição à construção desta amizade pública que se realiza na ANPEd como entidade e em cada reunião anual. Assim, tratarei de aspectos estruturais da relação entre esses dois documentos jurídicos, procurando indicar alguns pontos para reflexão de interesse específico para nós, da educação, no limite de tempo que temos aqui e para cumprir um papel de apenas iniciar os debates, que terão toda a reunião para se desdobrar.

\section{Constituição brasileira, direitos humanos e educação}

O tema da $31^{\text {a }}$ Reunião Anual da ANPEd celebra os 20 anos da Constituição brasileira, os 60 da Declaração Universal dos Direitos Humanos e os entrelaçamentos de ambos com a educação. São dois documentos jurídicos magnos, um internacional e outro nacional, que têm em comum o fato de haverem sido elaborados em momentos pós-ruptura (Arendt, 1989; Lafer \& Fonseca Júnior, 1994).

De fato, a elaboração de direitos com sentido universal vinha desde a Revolução Francesa, mas a Declaração Universal dos Direitos Humanos foi elaborada e proclamada como retorno a uma pauta da humanidade que fora interrompida pela ruptura que o totalitarismo nazista representou. Dessa forma, a Declaração Universal significa o momento fundador da reconstrução dos direitos humanos (Lafer \& Fonseca Júnior, 1994).

Da mesma forma, as lutas pela democracia no Brasil eram antigas, mas foram interrompidas pela ditadura militar que se instalou no país em 1964; a Constituição brasileira de 1988 foi elaborada e proclamada após a ruptura que o autoritarismo representou. Assim, significa o momento fundador da reconstrução democrática no Brasil.

Em ambos os casos, a educação tem papel central, exatamente por se tratar de reconstrução. Mais ainda: toda reconstrução é, de certa forma, uma nova construção, entrelaçando reivindicações antigas e novas, trazendo novas práticas e novas metodologias de luta. Mas, em vez de inventariar a educação em cada um desses documentos, parece ser mais oportuno discutir a relação do internacional com o nacional, uma vez que essas celebrações são tomadas aqui conjuntamente.

Há dois processos no campo jurídico que precisam ser mencionados. Um, de internacionalização dos direitos humanos, no momento de reconstrução pósSegunda Guerra Mundial. Outro, de internalização, que se refere à forma como os direitos humanos se relacionam e se impregnam nos direitos reconhecidos e positivados em nível nacional, que está em processo no Brasil e nos demais países signatários da Declaração Universal.

Pela internacionalização dos direitos humanos, o movimento se dá no sentido de expandir, cada vez mais, tudo que permita que, no mundo, cada vez mais seres humanos possam viver em condições dignas, garantindo o primado de que sejam todas e todos livres e iguais, como proclama o art. $1^{\circ}$ da Declaração Universal. Pela internalização, cada país busca as 
formas de fazer cumprir essas determinações da qual se tornou signatário.

Às críticas feitas à Declaração Universal, de que seriam vagos seus enunciados e, por isso, tenderiam a se tornar mera retórica inócua, o jurista Norberto Bobbio (1992) respondeu explicando que a Declaração Universal é um tipo de “conhecimento histórico profético”. Ou seja, foi o primeiro momento na história da humanidade em que houve o gesto de reunir-se uma significativa diversidade e um importante número de países para determinar o que entendiam como sendo possivelmente universal. Tiveram em mente os limites do momento e deixaram vasta tarefa para ser cumprida. Então, além de ser um conhecimento histórico profético, a Declaração Universal pode ser considerada como princípios de um programa a ser detalhado e cumprido ao longo do tempo, negociando a cada vez o que pode ser considerado universal.

Da mesma forma, nossa Constituição foi fruto da negociação e do acordo possível no momento em que foi promulgada. Reafirmou em si o poder constituinte do povo (art. $1^{\circ}$ parágrafo único: “Todo o poder emana do povo, que o exerce por meio de representantes eleitos ou diretamente, nos termos desta Constituição”), inovando na temática da possibilidade do exercício da democracia direta por meio da iniciativa popular, não existente em constituições brasileiras anteriores. Ao contrário da Declaração Universal, detalhou vários aspectos que, em outras circunstâncias, poderiam ficar para legislação complementar, em boa parte como forma de prevenir novos assaltos autoritários. Era como se o esforço constituinte daquele momento precisasse ser exaurido - embora não o tivesse sido ao máximo no entendimento de alguns, tanto que há constituintes que rejeitam a proposta que por fim assinam.

A Declaração Universal, sob tutela da Organização das Nações Unidas, vai se desdobrando e se especializando em diferentes grupos de direitos, buscando encontrar formas de proteção dos direitos universais em nível internacional. Foram então elaboradas convenções e pactos, hoje apresentados como seis documentos internacionais fundamentais na proteção dos direitos humanos para todas e todos, sendo considerados os seis instrumentos fundamentais de defesa dos direitos humanos:

- Convenção sobre a Eliminação de Todas as Formas de Discriminação Racial (1965);

- Pacto Internacional dos Direitos Civis e Políticos (1966);

- Pacto Internacional dos Direitos Econômicos, Sociais e Culturais (1966);

- Convenção sobre a Eliminação de Todas as Formas de Discriminação contra a Mulher (1979);

- Convenção contra a Tortura e outros Tratamentos ou Penas Cruéis, Desumanas ou Degradantes (1984);

- Convenção sobre os Direitos da Criança(1989).

A Constituição de 1988, em que pesem as inúmeras cautelas que a tornaram tão detalhista, igualmente pediu renovação de legislação que já vinha desatualizada - como o Código Civil, para citar um exemplo - e legislação complementar com valor constituinte, da qual para nós a de maior interesse é, logicamente, a Lei de Diretrizes e Bases da Educação Nacional, a lei n. 9.394/96, embora existam outros instrumentos legais e normativos, pós-Constituição, que são de alto relevo para nossas tarefas de pesquisa, ensino e cidadania, como o Estatuto da Criança e do Adolescente, entre outros. Voltaremos a esse ponto.

Nessa relação com a Declaração Universal, é importante mencionar o dispositivo que inclui como parte dos direitos do cidadão e da cidadã o atendimento a direitos estabelecidos no plano internacional. Assim:

Art. $5^{\circ}$, item LXXVIII $\S 2^{\circ}$ - Os direitos e garantias expressos nesta Constituição não excluem outros decorrentes do regime e dos princípios por ela adotados ou dos tratados internacionais em que a República Federativa do Brasil seja parte (em 2004 foi aprovada emenda, que introduziu os $\S 3^{\circ}$ e $4^{\circ}$, que não serão aqui tratados).

Assim, na perspectiva da internalização dos direitos humanos, seja a Declaração Universal, sejam documentos complementares, a Constituição Brasi- 
leira já previu, em 1988, que fossem incluídos como direitos dos cidadãos e cidadãs brasileiras. Assim, todos esses seis instrumentos fundamentais de proteção e promoção de direitos humanos originários dos debates para regulamentar internacionalmente a Declaração Universal são parte integrante de nossa ordem jurídica e podem ser apoio importante para a educação.

Mais ainda - e gostaria de ressaltar este ponto: a Constituição brasileira de 1988 tem relações importantes com a Declaração Universal e documentos internacionais correlatos que interligam esses documentos de forma profunda, em caminho de mão dupla, porque a Constituição resultou de processos e desencadeou dinâmicas que, se puderam se valer do acúmulo internacional na compreensão jurídica e do sistema internacional de proteção dos direitos humanos, acabaram também por ter influência no campo internacional. Vejamos.

A Constituição teve como característica resultar de processo de lutas e reivindicações que mobilizaram a sociedade civil organizada em oposição à ditadura. O recurso aos documentos internacionais de proteção dos direitos humanos foi fundamental e muitas vezes crucial tanto para invocar direitos cujo respeito se tinha como evidentes, denunciando assim o arbítrio, como para garantir mesmo a vida dos ativistas que se envolveram no confronto direto com as forças da repressão - e, muitas vezes, nem esse recurso teve como evitar o pior. De certa forma, é como se os aspectos que, da complexa negociação, resultaram mais progressistas da Constituição de 1988 fossem já afiliados à Declaração Universal, direta ou indiretamente, gerando entre os dois documentos ligações indeléveis.

Ao mesmo tempo, os aspectos que não foram diretamente incorporados à Declaração Universal, porque extrapolavam o contexto do que seria próprio à Constituição ou porque não passaram nas negociações ali, constituíram pautas em aberto, em continuidade de processo. Essa mobilização teve repercussão no campo internacional. De fato, o campo internacional se encontra em movimento permanente; vale lembrar que a década de 1990 em especial foi marcada por conferências mundiais voltadas para temas nos quais o Brasil teve grande envolvimento e participação por meio de delegados que levaram o debate em andamento no Brasil, influenciando os encaminhamentos internacionais.

O ponto delicado e relevante no contexto internacional é que todo envolvimento nas conferências, das quais resultam novas declarações e novos programas de ação, sempre ocorreu com dupla inserção dos países, fosse dos representantes governamentais (a cada momento), fosse dos representantes da sociedade civil, entendendo-se que os governos isoladamente, por seu mandato temporário e provisório, não podem representar sozinhos o Estado. Esse tipo de dinâmica leva a novas articulações internacionais, e, enquanto os governos se relacionam via diplomacia, a sociedade civil se relaciona por meio dos fóruns que elege para seus debates, como o Fórum Social Mundial, para citar o exemplo mais notável.

Algumas das conferências internacionais levadas a cabo nos anos de 1990 com importantes repercussões no campo jurídico internacional e nacional podem ser mencionadas brevemente, como forma de indicar o muito trabalho a realizar nessa perspectiva de pensar a educação de forma ampla, inserida em um contexto internacional, na perspectiva de conquistas de direitos, no plano individual e coletivo, enquanto se fortalece a democracia.

No campo da educação - e para colocarmos um marco temporal nesse processo de dupla mão entre o nacional e o internacional -, vale mencionar 1990, quando o Brasil participou da elaboração e assinou a Declaração e Programa de Ação da Conferência Mundial de Educação para Todos, realizada em Jomtien. Essa e conferências correlatas posteriores no campo da educação têm levado o Brasil a buscar atender compromissos internacionais assumidos que encontram profunda relação com as reivindicações internas, em nível nacional. Assim, pode-se afirmar que nos últimos 18 anos medidas voltadas para o pleno atendimento do direito à educação têm sido encaradas como política de Estado e não de governo, promovendo ganhos substanciais nos esforços realizados.

No campo social mais amplo e em sua relação com as conquistas internacionais que tiveram reper- 
cussão na educação, uma primeira vertente a mencionar é o fortalecimento dos movimentos indígenas, a partir da realização da Conferência Mundial dos Povos Indígenas, que se realizou como organização politicamente autônoma, em paralelo à Conferência Mundial das Nações Unidas sobre Meio Ambiente e Desenvolvimento, a "Rio-92". Marcos Terena, líder indígena brasileiro, foi o coordenador geral dessa Conferência, da qual resultou a "Carta da Terra”, que incorporou 109 recomendações feitas por 700 indígenas de todo o mundo, e a "Declaração da Kari-Oca", assim denominados os resultados da reunião por haver sido realizada na denominada "Aldeia Kari-Oca”, a trinta quilômetros da cidade do Rio de Janeiro (Terena, 2008). ${ }^{1}$ Essa conferência, que se afirmou como marco internacional, fortaleceu a emergência de novos participantes indígenas e de novas relações políticas na arena social, sendo que alguns dos protagonistas têm gradativamente sido reconhecidos como interlocutores na arena educacional, assumindo cada vez mais significado e espaço nos debates sobre a educação nacional. Para analisar as relações entre o nacional e o internacional, vale lembrar que a Constituição Federal de 1988 já havia incorporado grandes conquistas de direitos dos indígenas, em particular com relação ao respeito aos seus modos próprios de educação e aprendizagem, de valorização das línguas e culturas indígenas. Contudo, a presença internacional tratando do tema fortaleceu o que já era, então, aqui, letra constitucional.

A participação do Brasil na Conferência Mundial de Direitos Humanos, realizada em Viena em 1993, é outro exemplo da relação do campo social nacional com o internacional. Trouxe grande impacto ao tema da educação em direitos humanos, o qual foi um dos focos da conferência, além de sua influência nas políticas públicas de segurança e promoção de direitos

${ }^{1}$ No Brasil é utilizada a denominação “a Carioca” para referir-se à Conferência Mundial dos Povos Indígenas, enquanto na referência internacional ficou mais corrente o termo grafado como "Kari-Oca”. humanos como um todo, campos de pesquisa e trabalho que têm, frequentemente, relação com o campo educacional. Uma dessas influências é a relação com os direitos das mulheres (Women rights are human rights) e com a temática antirracista, repercutindo posteriormente em outra iniciativa da ONU, a Conferência Mundial contra o Racismo, realizada em Durban em 2001, que trouxe impacto na educação, seja pela proposta de inclusão de ações afirmativas (entre elas as cotas), seja no sentido de fortalecer o processo de aprovação da lei sobre ensino de história da África, recentemente modificada para inclusão da temática indígena. Retornaremos a este ponto.

Outra vertente importante, insuficientemente tratada na educação, ainda, é a Conferência Mundial sobre População e Desenvolvimento, realizada no Cairo em 1994, e a Conferência Mundial sobre Mulher e Desenvolvimento, realizada em Pequim em 1995; são referências de ainda outra vertente de educação em/para direitos humanos que trata de questões de gênero, de direitos sexuais e reprodutivos, da condição da mulher, estruturadas a partir da organização e das demandas dos movimentos de mulheres e organizações da sociedade civil. Inclui-se aí, por exemplo, a temática da descriminalização do aborto e de métodos contraceptivos, sendo inexplicável como tem sido deixada ao largo, com tão pouca atenção, no campo da educação, em que numericamente predominamos nós, mulheres.

Da mesma forma, a Conferência sobre Necessidades Educativas Especiais: Acesso e Qualidade, realizada em Salamanca, em 1994, trouxe importantes contribuições para o desenvolvimento de mais essa vertente de educação, em que se combinam direitos reconhecidos pela Constituição brasileira e a Declaração Universal.

A Conferência Mundial sobre Desenvolvimento Social realizada em Copenhague, em 1995, trouxe o debate sobre as relações entre o desenvolvimento, até então tomado mais em sentido econômico, e o ser humano como centro desse desenvolvimento, indicando o papel da educação nessa visão, então incipiente, de desenvolvimento humano. 


\section{Entre o internacional e o nacional: algumas conquistas e desafios}

É interessante debruçarmos nossa reflexão, agora, sobre alguns exemplos. Tomemos os direitos indígenas. Em paralelo e em interação com o movimento contra a ditadura, na época em que se intensificava a luta em prol da anistia, na segunda metade dos anos de 1970, iniciou-se movimento que reunia então jovens lideranças indígenas, reivindicando autonomia a toda tutela, fosse do Estado (seu tutor jurídico, pela ordem constitucional), fosse de instituições religiosas (em relação, por exemplo, à presença do Conselho Indigenista Missionário - CIMI) ou mesmo acadêmicas (nas delicadas relações com pesquisadores em geral e antropólogos em especial). Era o nascimento da União das Nações Indígenas (UNI). Essas jovens lideranças articularam-se com líderes indígenas com tradição, porém sem circulação no meio não-indígena, e com lideranças políticas não-indígenas respeitadas nacionalmente, mas sem tradição no tema, em um processo histórico de autorrepresentação que resultou em importantes avanços na Constituição de 1988. As reservas que tinham em relação a alguns dos antigos defensores dos povos indígenas foram, no processo constituinte, superadas pela negociação democrática, e, fortalecidos como protagonistas no processo, auxiliando a determinar novos rumos, tanto no cenário nacional quanto internacional, onde haviam ido buscar reforços para as conquistas internas. Um exemplo que diz respeito diretamente a nosso campo é o parágrafo $2^{\circ}$ do artigo 210 , que estabelece que o ensino fundamental regular será ministrado em língua portuguesa, assegurada às comunidades indígenas também a utilização de suas línguas maternas e processos próprios de aprendizagem.

Como parte do processo, algumas dessas lideranças passaram a ter assento em fóruns internacionais da ONU e da sociedade civil, com alta respeitabilidade, levando os resultados aqui obtidos para influenciar a definição de direitos indígenas no mundo. Para citar dois exemplos, Marcos Terena e Azelene Kaingang.

Tratando-se de processo dinâmico, seu desenvolvimento trouxe novas conquistas, como as que se veem na LDB (lei n. 9.394/96), com um capítulo específico para a educação indígena, e repercussões ainda em processo, como: participação de representação indígena no Conselho Nacional de Educação, sendo a primeira representante indígena a professora Francisca Novantino D’Angelo, a Chiquinha Pareci, no mesmo momento em que pela primeira vez o Conselho Nacional de Educação passava a ter representação afrodescendente, na pessoa da professora Petronilha Beatriz Gonçalves e Silva; inclusão dos Referenciais Curriculares Indígenas como parte das diretrizes curriculares nacionais; cursos de formação de professores indígenas, além de outras medidas correlatas.

Esse é um dos impactos mais evidentes da interação das garantias jurídicas internacionais com as conquistas nacionais, quando pensamos que, em mais de 500 anos de história pós-ocupação portuguesa, aqueles que aqui se encontravam apenas agora começam a ver horizonte de realização de seus direitos. Ao mesmo tempo, são ainda insuficientes os esforços efetivos para que o trabalho nas escolas não-indígenas pare de simplificar, em um homogeneizante "o índio", a presença de cerca de 240 diferentes grupos, falando mais de 180 línguas. $^{2}$

Outro exemplo é a presença da temática sobre direitos humanos e tolerância no campo da educação. A temática dos direitos humanos tradicionalmente esteve ligada, em termos acadêmicos, ao campo da ciência política, do direito, da sociologia, sobretudo pela íntima vinculação com temas de Estado, como a questão das violações de direitos civis e políticos, quando em situação de regimes de exceção; ou no contexto da violência social, como em casos de atuação das polícias e situações nas prisões, entre

${ }^{2}$ Exemplo da insuficiência ainda presente no tratamento da questão indígena no campo educacional é o pouco número de indígenas que completaram o ensino superior e o número ainda menor de indígenas que chegaram ou cursam a pós-graduação. O grupo de pesquisa que coordeno conta, por exemplo, com Daniel Monteiro Costa, o Daniel Munduruku, como pesquisador, doutorando no Programa de Pós-Graduação em Educação da Universidade de São Paulo, mas lamentavelmente ainda se trata de um dos raros casos. 
outros. Mas a presença da educação nesses temas foi ganhando papel próprio no mundo e em particular no Brasil, não apenas, como às vezes nos reivindicavam a nós do campo da educação, para oferecer "suporte didático" ao que pretendiam fazer.

Nesse sentido, o modo pelo qual se tem dado a mobilização político-educacional no Brasil, bem como as pautas que têm sido discutidas desde o Manifesto dos Pioneiros, de 1932, e desde a Campanha em Defesa da Escola Pública, nos anos de 1950, para tomar dois marcos históricos, fizeram com que os educadores ligados a essa temática criassem modos próprios de trabalho; há de fato uma diversidade interna notável, construindo diferentes articulações internacionais, auxiliando a propor temas, influenciando pautas, porque se dá uma prática de buscar excelência acadêmica e ao mesmo tempo manter constante diálogo com as forças sociais, em particular movimentos sociais ligados aos diversos temas em que atuamos.

Para dar um exemplo, a elaboração do documento Pluralidade Cultural, tema transversal dos Parâmetros Curriculares Nacionais, em aplicação por todo o Brasil desde 1997 (o qual é aqui apresentado como exercício, que gostaria de expor com toda modéstia, como responsável pela proposta e redação de seu conteúdo, como sabem), foi realizada com base em reivindicações históricas de movimentos sociais diversos; tomou como fonte de inspiração documentos de diversas agências da Organização das Nações Humanas, como o Centro de Direitos Humanos, ligado ao Alto Comissariado de Direitos Humanos da ONU, em Genebra, e em especial a Unesco, em Paris, com quem já mantinha colaboração desde 1994.

As experiências e documentos internacionais foram importantes para trazer possibilidades de abordagens que, combinadas ao trabalho da equipe dos PCN e ao debate em andamento no Brasil, permitiram a elaboração de uma proposta inovadora; esta retornou ao campo internacional, por um lado, com uma abordagem própria da temática da pluralidade cultural como ponto de partida para a compreensão do universal, tanto no que se refere à Declaração Universal dos Direitos Humanos, quanto ao universal no sentido nacional, da cidadania brasileira. A questão que perpassou todo o documento foi como a atenção a temas étnico-raciais - e mais especificamente relativos à diversidade cultural - poderia ser relevante para o conjunto da população brasileira, para a formação de todo e cada cidadão e cidadã de forma crítica.

Para solucionar essa questão no âmbito específico daquele documento curricular, foi necessário trazer e elaborar referenciais teóricos de diversas disciplinas, o que se mostrou particularmente relevante pelo caráter de tema transversal do mesmo. Um dos resultados dessa elaboração teórica consubstanciou-se na contribuição especificamente ligada à afirmação de que a pluralidade humana é a base da democracia. Por exemplo, em Hannah Arendt (1989) havia importante fonte a explorar, em sua análise sobre o totalitarismo, a qual explicita como a intolerância ao diverso estabeleceu os piores e mais terríveis regimes totalitários do século XX, a ponto de promover o genocídio, como no caso do Holocausto, um dos focos de seu estudo. Assim também a relevância das múltiplas abordagens, na direção não de um universal fechado, mas de algo em construção como um multiverso, foi possível trazer de Norberto Bobbio (1992). Trata-se, assim, de um tratamento do tema que parte do cotidiano (e outras abordagens referentes à filosofia ou à sociologia do cotidiano seriam possíveis) para construir a compreensão não apenas do universal, mas da própria inserção internacional. Essa abordagem da diversidade como ponto de partida para o tratamento dos direitos humanos, do ponto de vista educativo, acabou tendo influência internacional ${ }^{3}$.

Além disso, na perspectiva de política de Estado que atendia a demandas históricas dos movimentos

${ }^{3}$ Em 1998 e 1999, fui representante do Grupo de América Latina e Caribe (GRULAC), junto ao Grupo de Trabalho Temporário para Educação em Direitos Humanos, do Conselho Executivo da Unesco, ocasião em que foi possível expor essa abordagem, juntamente com a desenvolvida no Manual Direitos Humanos no Cotidiano, que coordenei, a partir da USP, para a então Secretaria Nacional dos Direitos Humanos, como colaboração com a UNESCO (Fischmann, 1998). 
sociais, com sua aplicação atravessando diferentes governos, de diferentes partidos, esse documento também abriu caminho para que fossem promulgadas e aplicadas duas leis posteriores, mas igualmente de reivindicação antiga: a) lei n. 10.639/03, que tornou obrigatório o ensino sobre História e Cultura AfroBrasileira, modificando a LDB; b) em março de 2008, nova alteração do mesmo dispositivo da LDB foi introduzida pela lei n. 11.645/08, que deu nova redação ao mesmo artigo da LDB, já alterado pela anterior (revogando-a assim).

Mais polêmico, a pedir ainda encaminhamento no campo legislativo brasileiro, e voltando ao artigo 210 da Constituição Federal, mas agora em seu parágrafo $1^{\circ}$, trata-se de exemplo que perpassa as seis décadas da Declaração Universal, relembrando apenas o que é do conhecimento de todos (por isso, perdoem porque vai de forma simplificada).

No artigo 26, item 3, da Declaração Universal, é afirmado o direito prioritário dos pais de escolher o gênero de educação que darão a seus filhos. Pois bem; esse artigo foi lembrado no Brasil quando de interesse de alguns grupos e tem sido esquecido exatamente quando é do interesse republicano. Foi lembrado no momento da promulgação da primeira LDB, a lei n. 4.024/61, e tem sido negado no que se refere ao ensino religioso nas escolas públicas.

Como é sabido, o projeto de lei apresentado em 1948 por Clemente Mariani para regulamentar o dispositivo constitucional que pela primeira vez atribuía à União a atribuição de legislar sobre diretrizes e bases da educação nacional trazia um projeto de uma escola pública laica, expandida para oito anos obrigatórios, em vez dos quatro do curso primário de então; era proposta como uma escola igual para todos, sem a presença da iniciativa privada nesse nível de ensino, embora não se negasse essa presença em outros níveis.

Ao longo da década de 1950, os mais diversos interesses fizeram com que esse projeto de lei ficasse engavetado; ao ser retomado, o segundo substitutivo de Carlos Lacerda utilizou a formulação da Declaração Universal para justificar a continuidade da iniciativa privada, com ênfase na possibilidade da garantia da escolha religiosa das famílias, se quisessem que seus filhos recebessem esse tipo de formação, garantindo assim a permanência das escolas, particulares ou comunitárias, como mais tarde a LDB 9.394/96 caracterizaria de tipo confessional. Os tempos eram de Guerra Fria e a perspectiva de "arrancar os filhos ao seio das famílias”, ainda que no sentido simbólico, por tratar de uma escola igualitária, encontrou eco. Não à toa, a lei n. 4.024 foi aprovada em dezembro de 1961, já em clima político tenso e dividido no Brasil.

Ora, com a expansão do antigo primário para oito anos, finalmente, e com as mudanças econômicas - em particular a partir do chamado Plano Collor -, escolas religiosas entraram em crise financeira. Adicionalmente, houve uma mudança acentuada, crescente e relativamente rápida da composição populacional no que se refere à afiliação religiosa, crescendo de forma notável o grupo evangélico, numa denominação mais ampla, como indicam os dados do IBGE.

Passa então a recrudescer a pressão, por parte da Igreja Católica Romana, em especial, pelo ensino religioso nas escolas públicas, com casos notáveis por sua inconstitucionalidade: Rio de Janeiro (Cunha, 2008) e São Paulo (Fischmann, 2008). O que se encaminha, então, é feito ao arrepio de diversos dispositivos constitucionais e mesmo desse próprio dispositivo da Declaração Universal, do direito da família de escolher a educação dos filhos, para articular essa Declaração internacional e a nossa Constituição.

Isso porque ao princípio constitucional de que a matrícula é facultativa para o estudante - que traz assim o direito da família à escolha do gênero de educação que quer dar a suas filhas e filhos - não tem correspondido, em estados e municípios em que se aplica, o efetivo direito à manifestação dos pais e dos estudantes, o que se faria pela manifestação expressa de sua opção por matrícula no ensino religioso. Estudos recentes demonstram que os estudantes sequer são informados dessa liberdade que têm garantida, de escolher se querem ou não assistir a aulas de ensino religioso; ou, pior ainda, a estrutura como o ensino religioso é oferecido sequer permite que os estudantes, em particular os mais jovens, das séries iniciais, tenham 
qualquer possibilidade à facultatividade, tornando o ensino religioso evidentemente inconstitucional. $\mathrm{O}$ constrangimento é a norma na prática, como se todos estivessem automaticamente matriculados, e manifestar sua discordância pode se constituir em tarefa inglória, a menos que se recorra à Justiça.

Observe-se que, se nos anos de 1950 a atenção ao campo internacional para alguns grupos foi conveniente a insistência no tema do direito de escolha dos pais em prol da iniciativa privada, nos anos de 1990 e de forma acirrada na primeira década do século 21 esse tema tem sido deixado totalmente ao largo de qualquer consideração das questões internacionais, como a temática das minorias religiosas. De fato, a queda do Muro de Berlim e a mudança da bipolaridade para as polaridades indefinidas e difusas (Lafer \& Fonseca Júnior, 1994) têm correspondido a um campo internacional tenso, onde conflitos com motivação religiosa têm sido frequentes. Tão forte manifestouse essa tendência, já com a Guerra dos Bálcãs, que a ONU proclamou a Declaração Internacional sobre os Direitos das Pessoas Pertencentes a Minorias Nacionais ou Étnicas, Religiosas e Linguísticas, que ampara todos os estudantes, de todos os níveis, desse tipo de constrangimento, exposição, discriminação e sofrimento por que hoje passam. Ademais, a própria análise do tema em relação à Constituição Federal de 1988 demonstra que atualmente o único caminho que possibilita o pleno respeito dos direitos humanos dos estudantes do ensino fundamental (e médio, já que alguns estados extrapolaram o enunciado do art. 210, parágrafo $1^{\circ}$ ) é a apresentação de uma proposta de emenda constitucional que suprima esse dispositivo da Constituição.

\section{Avanços jurídicos brasileiros e campo internacional: via de mão dupla}

Assim como o documento Pluralidade Cultural recebeu e levou influência ao campo internacional, há diversos exemplos que poderiam ser trazidos dessa via de mão dupla que é a inserção do Brasil no meio internacional que trabalha pela conquista de direitos.

A temática das cotas para negros e indígenas tam- bém tem exibido o quanto o campo jurídico internacional pode influenciar. Os princípios que regem a DUDH e documentos correlatos são marcados pela busca da equidade e uma visão distributiva de justiça. É claro que a questão fica complexa, frente a um mundo marcado pela desigualdade (no Brasil, o grau de desigualdade é ainda impressionante, mas quando consideramos a estrutura mundial infelizmente não estamos sozinhos), pela injustiça social, pelos muitos sacrificados pelos poucos, pelo cinismo da negação direta ou indireta dos direitos dos outros se os “meus” estão atendidos.

Mas no contexto das análises que nós, pesquisadoras e pesquisadores, podemos oferecer, é preciso reafirmar o direito à igualdade material, que pede que sejam adotadas ações afirmativas - e as cotas aí se encontram - voltadas para atender grupos nas singularidades e necessidades historicamente construídas de cada um. Isso de forma a garantir bases efetivas para a democracia, pelo reconhecimento do valor insubstituível da contribuição de cada grupo à composição política da sociedade. Esse debate vem amparado em documentos internacionais, como a já citada Convenção contra o Racismo, bem como a Convenção e Programa de Ação de Durban que resultou da Conferência Mundial contra o Racismo realizada na África do Sul em 2001.

A participação brasileira nessas iniciativas internacionais tem sido marcante, reconhecida mundialmente, não como exemplo de uma suposta democracia racial, o que não somos mesmo, mas como exemplo de enfrentamento do problema, de construção de análises, de estudos e argumentos que têm auxiliado a avançar o campo. São exemplos: a presença brasileira na transição de estratégia da UNESCO mundial, de redes regionais sobre tolerância para a estruturação de coalizões regionais de cidades contra racismo, discriminação e xenofobia. ${ }^{4}$ Também se incluem aqui as mobilizações

${ }^{4}$ Atuei nas duas estratégias, envolvendo outros colegas do Brasil e América Latina como um todo. As redes sobre tolerância tinham foco mais acadêmico, enquanto as coalizões são centradas nas cidades e têm nas cidades as protagonistas (Lazarev \& Fischmann, 2007). 
que levaram ao firme posicionamento latino-americano contra a mercantilização do ensino superior, como definido na ultima reunião realizada em Cartagena. Ou ainda a participação brasileira na definição dos termos da Convenção dos Direitos das Crianças, que foi aprovada e assinada mundialmente depois de nossa Constituição de 1988; beneficiou-se dos debates aqui havidos e que, mediante diversos testemunhos, ${ }^{5}$ reconhece a forte influência do movimento brasileiro em prol dos direitos de crianças e adolescentes, motivo pelo qual o Estatuto da Criança e do Adolescente também é considerado pioneiro em nível internacional.

Por essa presença brasileira tão marcante, é possível dizer que: (a) estamos plenamente inseridos na internacionalização dos direitos humanos, inclusive no caso da educação (participação em Jomtien, influência na convenção dos direitos das crianças etc.); (b) o processo de internalização dos direitos humanos no Brasil é antigo e, no caso da educação, seu atendimento vem sendo buscado, embora com pontos ainda de conflito, de complexidade variável; (c) a participação brasileira permitiria falar em uma “externalização” de nossas conquistas e processos nacionais. Ou seja, no processo de internacionalização, não somos passivos receptadores de decisões internacionais ou meros participantes formais; temos estado presentes de forma ativa nas decisões internacionais que, levando nossas influências, retornam ao Brasil, vindo moldar ou aperfeiçoar nossa ordem constitucional, baseada na Constituição brasileira de 1988; tal fato se dá, recordemos, em particular pela presença dos movimentos sociais e da interação histórica desses com a diplomacia brasileira. Como diz Celso Lafer (2005), o Brasil não pode sobreestimar seu papel internacional, mas não pode também subestimar-se, já que é um país respeitado nesse campo.

\section{Para finalizar, algumas propostas e reflexões}

A poetisa Emily Dickinson (1985, p. 45) ensina que

${ }^{5}$ Ver, por exemplo, apresentação da então diretora-geral do UNICEF (Gibbons, s.d.).
A água se aprende pela sede; [...]

A paz pela luta que se teve;

Por campas In Memoriam, o amor -

Os pássaros, pela neve. ${ }^{6}$

Aprendemos os direitos humanos pela violação, já ensina a literatura jurídica. Muitas vezes é a violação que alerta e faz perceber o direito que tínhamos e nem sabíamos. Mas na educação podemos atuar no sentido de que nossas pesquisas e nossas práticas auxiliem a formar essa consciência do direito a ter direitos, de que fala Hannah Arendt; a formar o conhecimento, desde cedo, dessas construções históricas que fazem a história humana, nos intervalos das diferentes opiniões, porque é a história que se constroi com diálogo e negociação, por meios não-violentos, ainda que muitas vezes possam ser conflitivos e de difícil negociação.

Propugnar que em nosso país todos possam ter conhecimentos de seus direitos é algo ligado inextricavelmente ao direito à educação. Reivindicar que o texto da Declaração Universal e os trechos da Constituição Federal de 1988 ligados à educação sejam distribuídos para todas as crianças é simples: os cartórios, ao registrar cada novo brasileiro, cada nova brasileira, poderiam dar as boas-vindas oferecendo os dois documentos junto com a certidão de nascimento, pois ali começa uma nova cidadania.

Livros didáticos, para todos os níveis, podem trazer os textos desses relevantes documentos jurídicos em suas capas ou como anexos. Os estabelecimentos de ensino, de todos os níveis, podem ter murais com os textos, podem distribuir pelas salas os temas. Propor que as universidades possam levar a seus estudantes o debate do papel da ciência no cumprimento dos direitos humanos. Por exemplo, o art. 27 propõe como direito humano o direito a participar do progresso científico - como está sendo feito isso em nossas IES?

Podemos e devemos propor linhas de financiamento específicas para interações ousadas e inovado-

\footnotetext{
${ }^{6}$ Do original: Water, is taught by thirst./ Land - by the Oceans passed./Transport - by throe -/Peace - by its battles told -/Love, by Memorial Mold - / Birds, by the Snow.
} 
ras, tanto junto ao Conselho Nacional de Desenvolvimento Científico e Tecnológico (CNPq) quanto às fundações de amparo à pesquisa estaduais (FAPs). Há uma arqueologia do saber sobre direitos humanos em sua relação com educação que está por ser realizada coletivamente - como houve um Projeto Genoma, é factível e importante uma grande cooperação em que possamos trabalhar juntos nesse sentido.

Por que não levar aos órgãos em que temos representação a proposta de programas especiais de financiamento de pesquisa; editais, ao CNPq, à CAPES e às fundações de apoio às pesquisas, em termos de avaliação, do debate de relevância social - em outras áreas se coloca a questão de patentes; para nós, o que é essa influência de agitar o debate e a opinião pública, impactando a política nacional? A imensa diversidade presente aqui, nos diversos grupos de trabalho e estudo da ANPEd, eles próprios frutos de longo processo histórico, abordam as muitas vertentes do direito à educação ou da educação como direito e que podem servir de base para propostas inovadoras de políticas públicas que entrelacem os direitos universais e tudo que nossa Constituição proclama e garante.

Hannah Arendt (1981), em A condição humana, destaca que há relação entre dois pares de características do processo de toda ação que precisam ser ponderados: a irreversibilidade e o poder de perdoar; e a imprevisibilidade e o poder de prometer. Se a questão do perdão hoje escapa ao escopo da reflexão, por envolver outras dinâmicas de alto relevo para a educação - como a reconciliação e seu impacto nas identidades e na política -, a questão da promessa é central aqui. Porque toda elaboração de um documento jurídico é uma promessa e, como discutido entre os juristas, fica a questão de como uma geração pode determinar o que a outra deve ou não fazer.

O jurista Ronald Dworkin (1978), por sua vez, pergunta qual a base ética para legislarmos e legarmos normas para as futuras gerações; e complementa a indagação: entenderão elas, as futuras gerações, o que se quis dizer? É válido o gesto?

Entendo que é nesses espaços existentes entre gerações que cabe dizer também o "eis aqui o que acho que é verdade”, construindo nesses espaços de amizade política que são, então, também temporais. Ou, para fazer um voto, à Brecht, de que os que virão depois de nós - no tempo em que o ser humano seja efetivamente amigo e parceiro do ser humano em todo o mundo possam pensar em nós com simpatia, compreendendo tudo por que lutamos e em que acreditamos, a ponto de a essas lutas dedicarmos nossas vidas.

Obrigada à ANPEd, mais uma vez, e a todas e todos que, nesta noite, aqui estão.

\section{Referências bibliográficas}

ARENDT, Hannah. A condição humana. Trad. Roberto Raposo; introd. Celso Lafer. Rio de Janeiro: Forense Universitária, 1981. . Homens em tempos sombrios. $1^{\mathrm{a}}$ reimpressão. Trad. Denise Bottman; posfácio Celso Lafer. São Paulo: Companhia das Letras, 1987.

Origens do totalitarismo. Trad. de Roberto Raposo.

São Paulo: Companhia das Letras, 1989.

BOBBIO, Norberto. A era dos direitos. $12^{\mathrm{a}}$ tiragem. Trad. Carlos Nelson Coutinho. Rio de Janeiro: Campus, 1992.

BRASIL. Constituição da República Federativa do Brasil. Diário Oficial da União, 5 de outubro de 1988.

. MINISTÉRIO DA EDUCAÇÃO. Pluralidade Cultu-

ral. Parâmetros Curriculares Nacionais. Temas transversais. Brasília: Secretária de Ensino Fundamental/MEC/UNESCO/PNUD, 1997. PRESIDÊNCIA DA REPÚBLICA. SECRETARIANA-

CIONAL DOS DIREITOS HUMANOS. Manual direitos humanos no cotidiano (Roseli Fischmann, Coordenadora geral). Brasília: Secretaria Nacional dos Direitos Humanos/Unesco/USP, 1998. Plano Nacional de Educação em Direitos Humanos 2006. Comitê Nacional de Educação em Direitos Humanos. Brasília: Secretaria Especial dos Direitos Humanos; MEC 2006. Disponível em: http://www.dhnet.org.br/dados/pp/edh/br/pnedh2/ pnedh_2.pdf. Acesso em 14 out. 2008.

BRASIL. SENADO FEDERAL. Lei 9.394, de 20 de dezembro de 1996. . lei n. 10.639, de 9 de janeiro de 2003. Disponível em: http://www.planalto.gov.br/ccivil_03/leis/2003/L10.639.htm. Acesso em 14 out. 2008.

. lei n. 11.645, de 10 março de 2008. Disponível em: http://www.planalto.gov.br/ccivil_03/_Ato2007-2010/2008/Lei/ L11645.htm. Acesso em 14 out. 2008. 
CUNHA, Luiz Antonio. O ensino religioso no Rio de Janeiro: história e conjuntura política. In: FISCHMANN, Roseli (Org.). Ensino religioso em escolas públicas: impactos sobre o Estado Laico. São Paulo: FAFE/ FEUSP/ PROSARE/ MacArthur Foundation, Factash, 2008. p. 105-131.

DICKINSON, Emily. Uma centena de poemas. Edição Bilíngüe. Trad., intr. e notas Aíla de Oliveira Gomes. Apres. Paulo Rónai, Pref. Ashley Brown. São Paulo: T.A. Queiroz, 1985.

DWORKIN, Ronald. Taking rights seriously. Cambridge: Harvard University Press, 1978.

FISCHMANN, Roseli. Estratégias de superação da discriminação ética e religiosa no Brasil. In: PINHEIRO, Paulo Sérgio; GUIMARÃES, Samuel Pinheiro (Orgs.). Direitos Humanos no Século XXI. São Paulo: MRE/IPRI, 1998. p. 959-985.

. Do transversal ao inconstitucional: o caso da normatização do ensino religioso nas escolas públicas no Estado de São Paulo após 2001. In: FISCHMANN, Roseli (Org.). Ensino religioso em escolas públicas: impactos sobre o Estado Laico. São Paulo: FAFE/ FEUSP/ PROSARE/ MacArthur Foundation, Factash, 2008. p. 132-152.

GIBBONS, Elizabeth D. The Convention on the Rights of the Child and Implementation of Economic, Social and Cultural Rights in Latin America. S.d. Disponível em: <http://www.capabilityapproach. com/pubs/Gibbons07.pdf>. Acesso em: 21 out. 2008.

LAFER, Celso. A internacionalização dos direitos humanos - Constituição, Racismo e Relações Internacionais. Barueri: Manole, 2005.

.; FONSECA JÚNIOR, Gelson. Questões para a diplo-

macia no contexto internacional das polaridades indefinidas (notas analíticas e algumas sugestões). In: FONSECA JÚNIOR, Gelson; CASTRO, Sergio Henrique Nabuco de. Temas de política externa brasileira II. V. 1. Rio de Janeiro: Paz e Terra/Fundação Alexandre de Gusmão/Instituto de Pesquisas de Relações Internacionais, 1994. p. 49-77.

LAZAREV, Serguei; FISCHMANN, Roseli. From tolerance to intercultural dialogue: an interview. In: Dossier Kelman - Notandum Libro 9. São Paulo/Porto, jun. 2007. p. 62-63. Disponível em: <www.hottopos.com>. Acesso em: 14 out. 2008.

ONU. Charter of the United Nations. We the peoples of the United Nations. . . United for a Better World. San Francisco: 1945. Disponível em: <http://www.un.org/aboutun/charter/>. Acesso em: 13 out. 2008.

TERENA, Marcos. Entrevista. In: "Indígenas querem ser ouvidos sobre combate à mudança climática”, Rádio ONU. Disponível em: $<$ http://www.thebrasilians.com/mostracoluna.php?colunista=16>. Acesso em: 12 out. 2008.
UNESCO. Declaração de Princípios sobre a Tolerância. Publicação USP. Disponível em: <http://unesdoc.unesco.org/ images/0013/001315/131524porb.pdf>. Acesso em: 14 out. 2008. UNITED NATIONS. Universal Declaration of Human Rights Portuguese, 1948. In: Office of High Commissioner for Human Rights - Portuguese version. Source: United Nations Information Centre. Disponível em: <http://www.unhchr.ch/udhr/lang/por. htm>. Acesso em: 13 out. 2008.

ROSELI FISCHMANN, doutora em filosofia e história da educação pela Universidade de São Paulo (USP), é livre docente no Programa de Pós-Graduação em Educação da mesma instituição. Foi professora visitante da Universidade Harvard (Estados Unidos) e integrou o grupo de trabalho sobre Educação em Direitos Humanos da UNESCO (Paris). Redigiu o documento “Pluralidade cultural”, integrando a equipe dos PCNs do Ministério da Educação, e foi coordenadora geral da elaboração do Manual Direitos Humanos no Cotidiano, em colaboração com a Secretaria Nacional dos Direitos Humanos, da UNESCO e da USP. Coordena o Grupo de Pesquisa Discriminação, Preconceito, Estigma, no qual desenvolve pesquisas sobre educação, direitos humanos, direitos de minorias e sua relação com o Estado laico. Publicações mais importantes: organizou Escola brasileira: temas e estudos (São Paulo: Atlas, 1987); Medios masivos de comunicación, y responsabilidad educativa: indignación y derechos civiles (In: Psicologia política del nuevo siglo: una ventana a la cidadania. México: Sociedad Mexicana de Psicologia Sócial/Secretaria de Educación Pública, 1999); Crianças e adolescentes: construindo uma cultura da tolerância (São Paulo: EDUSP, 2001); Povos indígenas e tolerância: construindo práticas de respeito e solidariedade (São Paulo: EDUSP, 2001); Historical and legal remarks on cultural diversity and higher education in Brazil in the context of the school system (Higher Education Policy - The Quarterly Journal of the International Assocation of Universities (IAU), v. 18, p. 375-395, 2005); Dossier Kelman - Notandum Libro-9 (São Paulo/Porto: Mandruvá, 2007); Estado laico (São Paulo: Memorial da América Latina, 2008). Pesquisa atual: “O caráter educativo da laicidade do Estado para a esfera pública: alcance da ação do Ministério Público em defesa da cidadania e da democracia” em parceria com o Movimento do Ministério Público Democrático e financiamento da Fundação de Apoio à Pesquisa do Estado de São Paulo.E-mail: roselif@usp.br

Recebido em novembro de 2008 Aprovado em dezembro de 2008 